\title{
Transhiatal Esophagectomy
}

National Cancer Institute

\section{Source}

National Cancer Institute. Transhiatal Esophagectomy. NCI Thesaurus. Code C140888.

A type of esophagectomy where the esophageal tumor is removed through an abdominal incision and a left neck incision, without a thoracotomy. The esophagogastric anastomosis is located in the neck. 